\title{
Bi-Cl (Bismuth-Chlorine)
}

\section{H. Okamoto}

The $\mathrm{Bi}-\mathrm{Cl}$ phase diagram shown in Fig. 1 has been redrawn from [Massalski2] by including an additional new phase, $\mathrm{Bi}_{7} \mathrm{Cl}_{10}$, discovered by [2005Ham]. The peritectoid formation temperature of $\mathrm{Bi}_{7} \mathrm{Cl}_{10}$ is $190 \pm 5{ }^{\circ} \mathrm{C}$.

$\mathrm{Bi}-\mathrm{Cl}$ crystal structure data are given in Table 1.

\section{Reference}

2005Ham: S. Hampel, P. Schmidt, and M. Ruck, Synthesis, Thermochemical Properties, and Crystal Structure of $\mathrm{Bi}_{7} \mathrm{Cl}_{10}$. Z. Anorg. Allg. Chem., 2005, 631, p 272-283, in German

Table 1 Bi-Cl crystal structure data

\begin{tabular}{|c|c|c|c|c|c|}
\hline Phase & Composition, at.\% Cl & Pearson symbol & Space group & Strukturbericht designation & Prototype \\
\hline (Bi) & 0 & $h R 2$ & $R \overline{3} m$ & $A 7$ & $\alpha$ As \\
\hline $\mathrm{Bi}_{6} \mathrm{Cl}_{7}$ & 53.8 & $o P 104$ & Pnnm & $\ldots$ & $\ldots$ \\
\hline $\mathrm{Bi}_{7} \mathrm{Cl}_{10}$ & 58.8 & $t I 1088$ & $I 4_{1} /$ acd & $\ldots$ & $\ldots$ \\
\hline $\mathrm{BiCl}_{3}$ & 75 & $o P 16$ & $P n 2_{1} a$ & $\ldots$ & $\ldots$ \\
\hline$(\mathrm{Cl})$ & 100 & $o C 8$ & Cmca & $A 14$ & I \\
\hline
\end{tabular}

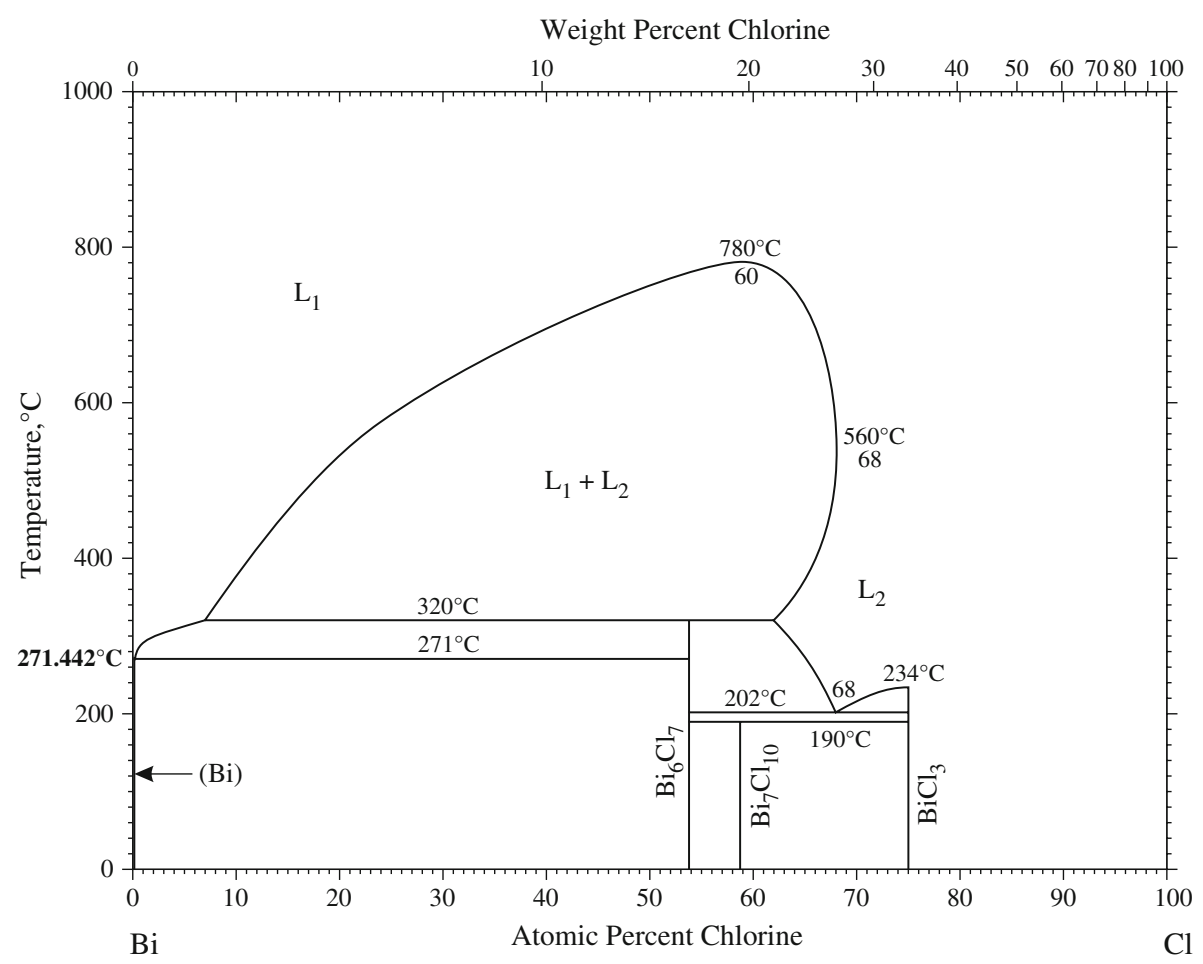

Fig. 1 Bi-Cl phase diagram 